\title{
Atribuições da equipe multiprofissional diante do processo de doação de órgãos e tecidos
}

Assignments of the multiprofessional team to the process of donation of organs and tissues Atribuciones del equipo multiprofesional ante el proceso de donación de órganos y tejidos

Brenda Lícia Martins da Silva", Iralice Leite Lima², Vanessa Leal Lira ${ }^{2}$, Francisco Lucas de Lima Fontes $^{1 *}$, Mércia Cycilia de França Lopes ${ }^{1}$, Josélia Costa Soares ${ }^{1}$, Edvan Santana ${ }^{1}$, Fernanda de Carvalho da Cunha ${ }^{1}$, Bruna Furtado Sena de Queiroz ${ }^{3}$, Camila de Araújo Batista ${ }^{1}$, Yasmin Nunes de Alencar ${ }^{1}$, Erika Ravana Sampaio Barbosa Macêdo ${ }^{1}$, Geicielly da Silva Lima ${ }^{1}$, Regina Célia Soares de Sousa Ponciano ${ }^{4}$, Hilda Carmem de Oliveira Fontes Rodrigues Santos ${ }^{5}$.

\section{RESUMO}

Objetivo: Descrever as atribuições da equipe multiprofissional diante do processo de doação de órgãos e tecidos para transplantes sob a perspectiva de acadêmicos de Enfermagem. Relato de experiência: Pôdese observar e conhecer as atribuições que a equipe multiprofissional desempenha no processo de doação de órgãos e tecidos. Destaque deve ser dado ao profissional enfermeiro, que exerce grande quantidade de funções. Conclusão: Por meio da experiência do estágio no projeto de extensão, verificou-se o árduo trabalho de cada categoria profissional, bem como foi permitido auxílio nas atividades diárias do projeto. $\mathrm{Na}$ Organização de Procura de Órgãos e Tecidos observou-se, principalmente, a sobrecarga de atribuições do enfermeiro, ao passo que também visualizou-se que, na sua ausência, o processo de trabalho estagna-se.

Palavras-chave: Morte encefálica, Obtenção de tecidos e órgãos, Equipe multiprofissional.

\begin{abstract}
Objective: To describe the attributions of the multiprofessional team before the process of donation of organs and tissues for transplants from the perspective of Nursing students. Experience report: It was possible to observe and to know the attributions that the multiprofessional team performs in the process of organ and tissue donation. Emphasis should be given to the professional nurse, who performs a great number of functions. Conclusion: Through the experience of the internship in the extension project, the hard work of each professional category was verified, as well as aid was allowed in the daily activities of the project. In the Organization for the Search of Organs and Tissues, it was observed, mainly, the overload of the nurses' assignments, while also visualizing that, in their absence, the work process stagnates.
\end{abstract}

Keywords: Brain death, Tissue and organ procurement, Patient care team.

\section{RESUMEN}

Objetivo: Describir las atribuciones del equipo multiprofesional ante el proceso de donación de órganos y tejidos para trasplantes desde la perspectiva de académicos de Enfermería. Relato de experiencia: Se pudo observar y conocer las atribuciones que el equipo multiprofesional desempeña en el proceso de donación de órganos y tejidos. El destaque debe ser dado al profesional enfermero, que ejerce una gran cantidad de funciones. Conclusión: A través de la experiencia de la etapa en el proyecto de extensión, se verificó el arduo trabajo de cada categoría profesional, así como se permitió ayuda en las actividades diarias del proyecto. En

1 Faculdade UNINASSAU - Campus Redenção. Teresina, Piauí, Brasil. *E-mail:Iucasfontesenf@hotmail.com

2 Universidade Estadual do Piauí. Teresina, Piauí, Brasil.

${ }^{3}$ Faculdade FACID - Wyden. Teresina, Piauí, Brasil.

${ }^{4}$ Faculdade de Tecnologia e Educação Superior Profissional. Teresina, Piauí, Brasil.

${ }^{5}$ Faculdade Estácio CEUT. Teresina, Piauí, Brasil. 
la Organización de Búsqueda de Órganos y Tejidos se observó, principalmente, la sobrecarga de atribuciones del enfermero, mientras que también se visualizó que, en su ausencia, el proceso de trabajo se interrumpe.

Palabras-clave: Muerte encefálica, Obtención de tejidos y órganos, Grupo de atención al paciente.

\section{INTRODUÇÃO}

De 1950 para cá, procedimentos de doação e transplante de órgãos e tecidos evoluíram significativamente como intervenções terapêuticas úteis a doenças terminais cardíacas, pulmonares, hepáticas e metabólicas, além de patologias associadas a tecidos e células. Esse progresso envolve diversos fatores como aceitação cultural, avanços legislativos e jurídicos na facilitação da doação e transplante, técnicas de captação e procedimentos de distribuição (WATSON CJE e DARK JH, 2012).

A remoção de órgãos e tecidos é regulamentada por lei e só pode ser facultada após execução de testes de triagem diagnóstica no doador, respeitando-se os intervalos de tempo próprios a cada faixa etária. A Central de Notificação, Captação e Distribuição de Órgãos e Tecidos precisa ser notificada obrigatoriamente por todas as instituições de saúde, mesmo naqueles casos de suspeita diagnóstica, ainda que a condição clínica e intenção da família sejam desconhecidas (CORREIA WLB et al., 2018).

No período de 2010 a 2017 o número de doadores efetivos no Brasil elevou-se 69\%, progredindo de 9,9 para 16,6 por milhão de população. Somente no ano de 2017 essa evolução foi de 14\%, o que representa importante aumento nos transplantes de pulmonares $(21,7 \%)$, hepáticos $(12,1 \%)$, renais $(7,5 \%)$ e cardíacos (6,4\%). No mesmo ano, o Piauí registrou 26 doadores efetivos, alcançando a marca de 9,3 transplantes realizados por milhão de habitantes. Mas o número de potenciais doadores foi maior (111). Em 2017 foram realizados 189 transplantes no estado piauiense, sendo 159 de córnea e 30 de rim (ASSOCIAÇÃO BRASILEIRA DE TRANSPLANTE DE ÓRGÃOS, 2017).

O processo de doação engloba investigação de circunstâncias associadas ao doador, podendo este ser vivo ou falecido (com morte encefálica confirmada). Para que a doação ocorra, é necessária avaliação minuciosa do estado de saúde do doador, comprovada por meio de exames a fim de evitar que o receptor seja afetado por patologias, o que prejudicaria assim sua saúde. A compatibilidade doador versus receptor deve respeitar todas as disposições presentes na Lei № 9.434 de 1997, que dispõe sobre a retirada de órgãos e tecidos com finalidade de transplante e terapêutica (BRASIL, 1997).

Mesmo com todos os avanços, alguns desafios ainda são enfrentados para efetivação da doação como a ausência de notificação de morte encefálica e o manejo inadequado dos órgãos. Evidencia-se, portanto, a relevância de qualificação da equipe multiprofissional comprometida no processo, com vistas a impedir a perda do potencial doador, consequentemente alavancando o número de doações e diminuindo o tempo na fila de espera (MENDES KDS et al., 2012).

A Organização de Procura de Órgãos e Tecidos (OPO) do estado do Piauí segue minuciosamente a Resolução mais recente do Conselho Federal de Medicina, que define os critérios e procedimentos para determinação de morte encefálica. O processo de captação e distribuição é um evento amplo onde há uma equipe multiprofissional atuante composta por médicos, enfermeiros, psicólogos e técnicos de Enfermagem no trabalho conjunto para garantir que todo cidadão tenha direito ao diagnóstico seguro da morte, almejando que esse momento seja o menos doloroso possível para seus familiares (BRITO AAO et al., 2015).

A OPO trabalha diretamente com o paciente na garantia da manutenção do potencial doador, da estabilidade hemodinâmica e realização de sorologias, garantindo assim a viabilidade e qualidade dos órgãos passíveis de doação. Apenas após confirmado o diagnóstico de morte encefálica, a família passa a ser orientada sobre o processo de doação de órgãos (PINHEIRO ES et al., 2015).

De acordo com o contexto abordado, este estudo teve como objetivo descrever as atribuições da equipe multiprofissional diante do processo de doação de órgãos e tecidos para transplantes sob a perspectiva de acadêmicos de Enfermagem. 


\section{RELATO DE EXPERIÊNCIA}

O relato foi vivenciado por acadêmicos de diversas instituições de ensino superior de Teresina, estado do Piauí, no primeiro semestre de 2018. O plano de ação foi desenvolvido a partir de um projeto de extensão intitulado "Liga Acadêmica de Busca Ativa de Potencial Doador de Órgãos e Tecidos para Transplantes" da OPO do estado. Esse projeto de extensão teve como carga horária total 180 horas.

O seletivo de acadêmicos para este projeto ocorre semestralmente e consiste em duas fases: avaliação do currículo e posterior entrevista para análise do perfil e disponibilidade com os selecionados da primeira etapa.

A OPO fica localizada em um hospital estadual referência em ensino na capital piauiense, e é formada por uma equipe multiprofissional que conta com enfermeiros, médico, psicólogos e técnicos de Enfermagem atuantes desde a busca de potencial doador, entrevista familiar, até à captação dos órgãos.

A organização funciona todos os dias da semana, 24 horas por dia. No entanto, os ligantes participaram em regime de plantão com carga horária de 16 horas semanais, sendo 12 horas de serviço diurno e 4 horas de serviço noturno, de forma que não prejudicasse as atividades curriculares da graduação. Os estágios ocorreram nas redes estadual e municipal de saúde.

Antes da ida dos acadêmicos aos campos de captação de órgãos, todos os participantes do projeto foram submetidos à capacitação teórico-prática sobre os aspectos que seriam trabalhados e as atividades usualmente executadas pelo profissional de Enfermagem no processo de doação e captação de órgãos.

Dentre as atividades realizadas pelos acadêmicos, a principal consistia na busca ativa, que visava identificar o potencial doador de órgãos e tecidos tanto no hospital sede, quanto no Instituto Médico Legal (IML), além de outros estabelecimentos de saúde definidos previamente por questões geográficas e populacionais sob recomendação da Central de Transplantes.

Todo evento referente às buscas era devidamente notificado em fichas específicas. No caso do paciente cadavérico, na ficha de notificação de óbitos após a parada cardiorrespiratória. Já para o paciente hospitalizado em suspeita de morte encefálica, na ficha que deveria ser preenchida para abertura de Protocolo de morte encefálica. O preenchimento desses impressos era de responsabilidade da enfermeira da OPO, bem como a realização da evolução de eventos na folha anexada ao impresso aplicado ao paciente hospitalizado.

Nas rotinas da OPO, quando os óbitos ocorriam após parada cardiorrespiratória, somente as córneas poderiam ser captadas, isso atendendo a alguns critérios, a saber: óbito que não ultrapassasse 6 horas de ocorrido, de etiologia conhecida, corpo identificado, com faixa etária de 3 a 75 anos, ausência de tatuagens realizadas há pelo menos um ano e inexistência de condições de risco à transmissão de doenças após o transplante. O enfermeiro, profissional responsável por realizar a enucleação, avaliava a integridade e qualidade das córneas antes da entrevista ao familiar, para que isso não gerasse falsas expectativas acerca da doação.

Para o paciente hospitalizado, a identificação do potencial doador era realizada pela enfermeira. Esta, ao chegar aos estabelecimentos de saúde dirigia-se aos setores críticos buscando inicialmente pacientes que estivessem com escore 3 na Escala de Coma de Glasgow. Encontrado algum paciente nesta situação, realizava-se juntamente com o acadêmico a investigação acerca do histórico do indivíduo, verificando-se os parâmetros necessários. Os aspectos analisados eram: idade, que deveria ser de 3 a 75 anos, causa do coma conhecido, patologias, nas quais tinham contraindicações absolutas os tumores malignos, sorologia positiva para HIV ou para HTLV I e II, sepse ativa e não controlada e tuberculose em atividade.

Para o desenvolvimento das atividades da OPO realizavam-se visitas eletivas que contavam com a participação de uma enfermeira, um técnico de Enfermagem e um acadêmico. Ao chegar aos estabelecimentos de saúde os membros da organização dirigiam-se aos setores críticos e necrotério e suas ações obedeciam ao seguinte fluxo (Figura 1). 
Figura 1 - Fluxograma de ações da OPO para busca ativa.

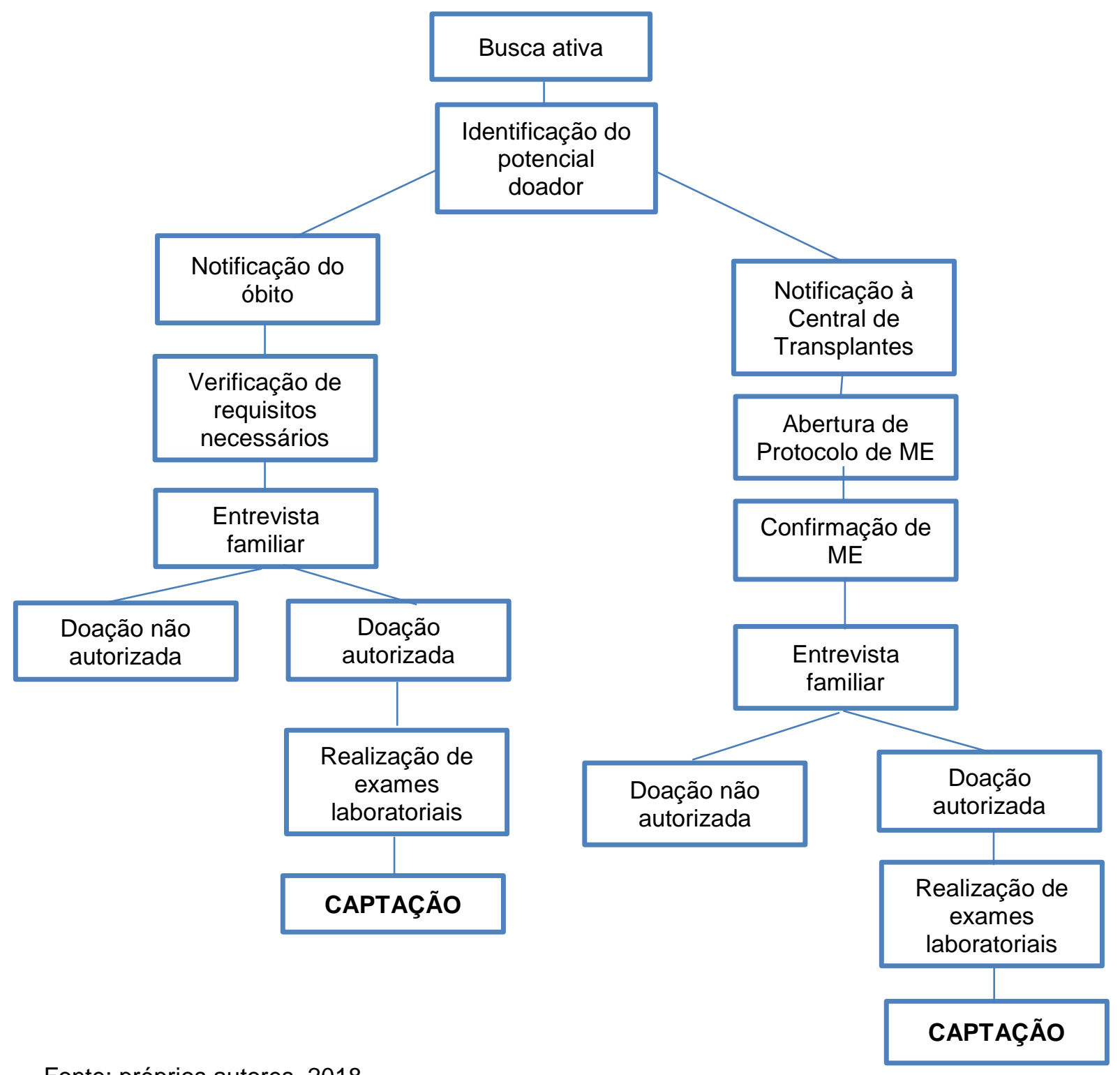

Fonte: próprios autores, 2018.

Para o diagnóstico de morte encefálica por meio do protocolo eram necessários seguimento de alguns critérios clínicos do paciente. O potencial doador não podia estar hipotérmico (temperatura $<35^{\circ} \mathrm{C}$ ) e, se em sedoanalgesia, esta deveria ser suspensa pelas 24 horas seguintes para avaliação. Após a confirmação da morte encefálica, o médico informava aos familiares sobre o diagnóstico. Somente após este momento, a enfermeira e o acadêmico de Enfermagem da OPO estavam aptos a se apresentarem aos familiares e realizarem a entrevista.

Destaca-se aqui a importância do psicólogo durante a entrevista. Sua atuação neste momento poderia contribuir bastante para o desenvolvimento de uma conversa mais efetiva, entretanto, a maioria das entrevistas eram realizadas sem a presença deste profissional, ficando a cargo apenas do enfermeiro sua realização para posterior encontro com o psicólogo, o que fragmenta a assistência.

Diante das etapas que envolviam o processo de doação de múltiplos órgãos e tecidos havia uma equipe multiprofissional atuante. Esta deveria agir de maneira articulada de forma que todas as ações fossem distribuídas a cada membro da equipe buscando celeridade no fechamento do protocolo, mesmo que não 
houvesse autorização de doação pela família. As atribuições que cada profissional desempenhava nas rotinas da OPO do Piauí estão elencadas no quadro (Quadro 1).

Quadro 1 - Atribuições da equipe multiprofissional da OPO diante do processo de doação de órgãos e tecidos para transplantes.

\begin{tabular}{|c|c|}
\hline CATEGORIA PROFISSIONAL & ATRIBUIÇÕES \\
\hline Enfermeiro & $\begin{array}{l}\text { - Realização de busca ativa; } \\
\text { - Histórico do paciente; } \\
\text { - Avaliação hemodinâmica; } \\
\text { - Notificação à Central de Transplantes; } \\
\text { - Preenchimento de impressos; } \\
\text { - Solicitação de avaliação médica; } \\
\text { - Orientação à equipe da instituição em que o potencial doador } \\
\text { encontra-se acerca da manutençâo hemodinâmica; } \\
\text { - Entrevista familiar; } \\
\text { - Coleta de material para exames; } \\
\text { - Preparo de caixa térmica para conservação de órgãos; } \\
\text { - Operação do maquinário para circulação extracorpórea; } \\
\text { - Realização da enucleação ocular; } \\
\text { - Orientações à família acerca do processo e tempo de captação; } \\
\text { - Entrega do corpo aos familiares; } \\
\text { - Educação em saúde. }\end{array}$ \\
\hline Médico & $\begin{array}{l}\text { - Solicitação de exames laboratoriais; } \\
\text { - Realização de abertura e fechamento de protocolo de morte } \\
\text { encefálica por meio de realização de exames clínicos e de imagem; } \\
\text { - Captação de órgãos; } \\
\text { - Avaliação da viabilidade de cada órgão; }\end{array}$ \\
\hline Psicólogo & $\begin{array}{l}\text { - Auxílio ao enfermeiro na entrevista familiar; } \\
\text { - Oferecimento de apoio emocional aos familiares por meio de escuta } \\
\text { ativa. }\end{array}$ \\
\hline Técnico de Enfermagem & $\begin{array}{l}\text { - Auxílio ao enfermeiro na busca ativa; } \\
\text { - Avaliação das condições clínicas do potencial doador cadavérico; } \\
\text { - Preenchimento de impressos; } \\
\text { - Auxiliar na realização da enucleação ocular; } \\
\text { - Entrega do corpo aos familiares. }\end{array}$ \\
\hline
\end{tabular}

Fonte: próprios autores, 2018.

A entrevista familiar era um momento tenso e de muitas responsabilidades para a enfermeira da OPO. Esta deveria mostrar-se empática à situação, entretanto necessitava manter-se em postura firme, ao explicar seu trabalho, sanando todas as dúvidas dos familiares, utilizando-se da persuasão a fim de mostrar à família os benefícios que uma doação proporcionaria à sociedade.

Nas ocasiões em que o familiar responsável mostrava-se favorável à doação, este, bem como duas testemunhas, assinavam o Termo de Consentimento Informado, documento que comprova a autorização para a retirada de órgãos e/ou tecidos. Preenchia-se também o Relatório Social do Doador, que consiste em uma investigação acerca da vida pregressa e comportamental do doador eletivo. Após uma doação autorizada, toda a equipe da OPO juntamente com a Central de Transplantes se articulava para que o processo de doação ocorresse o mais rapidamente possível a fim de minimizar a espera pela entrega do corpo à família doadora. 


\section{DISCUSSÃO}

O enfermeiro foi o profissional com mais responsabilidades identificadas dentro da OPO do Piauí. Negreiros FDS et al. (2017) cita que o papel deste profissional no processo de transplante é servir de elo, coordenando a equipe multiprofissional. Os demais membros da equipe são igualmente responsáveis pela qualidade de seus serviços, garantindo sucesso de todo o processo.

Como destacado, cabia ao enfermeiro a captação das córneas nos casos de morte por parada cardiorrespiratória. A enucleação ocular é permitida ao profissional por meio da Resolução № 292 do Conselho Federal de Enfermagem, de 02 de maio de 2004, que estabelece a realização de enucleação do globo ocular desde que tecnicamente habilitado pela Associação Pan-americana de Banco de Olhos. Esta Resolução também normatiza a participação da Enfermagem (enfermeiro e técnico de Enfermagem) no processo de transplante e doação de órgãos (CONSELHO FEDERAL DE ENFERMAGEM, 2004).

Já nos casos de morte encefálica, além das córneas, outros órgãos poderiam ser viáveis à doação. A Resolução do Conselho Federal de Medicina № 2.173 de 2017 define a morte encefálica como a perda absoluta e irreversível das atividades encefálicas por razão conhecida, confirmada e viável ao quadro clínico. Esta Resolução também instituiu novas condutas que proporcionam mais segurança e acurácia do protocolo (CONSELHO FEDERAL DE MEDICINA, 2017).

De modo a conferir maior segurança, na suspeita de morte encefálica inicia-se a realização da triagem sorológica do potencial doador, após solicitação médica. Em casos de sorologia positiva, elimina-se a posterior etapa que discutiria com a família a viabilidade de doação de órgãos e tecidos. Nos casos negativos, dá-se continuidade ao processo de manejo do doador, busca de consentimento familiar e captação (BRITO AAO et al., 2015).

Para se chegar ao diagnóstico de morte encefálica, o médico deve realizar obrigatoriamente, ao menos, dois exames clínicos, que confirmem de forma fidedigna o coma não perceptivo, ausência de reatividade supraespinhal manifestada pela ausência dos reflexos fotomotor, córneo-palpebral, oculocefálico, vestíbulo-calórico e de tosse; teste de apneia confirmando a ausência de movimentos respiratórios após estimulação máxima dos centros respiratórios; exame imagem complementar comprovando ausência de atividade encefálica (CONSELHO FEDERAL DE MEDICINA, 2017). Esse diagnóstico deve ser certificado por dois médicos sem vínculo com as equipes de remoção e de transplante (BRASIL, 1997).

A perda de potenciais doadores falecidos antes da captação de órgãos é fato comum devido ao tempo prolongado para conclusão do diagnóstico e da demora promovida por fatores administrativos e assistenciais. No que diz respeito aos fatores assistenciais, lamentavelmente falhas no manejo do doador são frequentes pela equipe responsável pelo falecido, o que expõe desconhecimento da equipe prestadora de assistência acerca da manutenção intensiva até a ocorrência da doação (PINHEIRO ES et al., 2015).

Esse desconhecimento não se aplica apenas aos profissionais, mas também à população, como evidenciado pelo estudo de Brito AAO et al. (2015), que expôs o número elevado de recusas à doação, muito provavelmente devido à insipiência do conceito de morte encefálica e a valores culturais que perduram até os dias de hoje. Outro estudo realizado em 2018 mostrou desconhecimento dos profissionais acerca da legislação vigente a respeito do processo de doação, captação e transplante de órgãos, bem como do suporte para manutenção dos padrões hemodinâmicos do doador antes deste ser encaminhado ao centro cirúrgico (GOMES CNS et al., 2018).

Faz-se necessário, portanto, sistematizar a assistência objetivando converter o potencial doador em doador efetivo por meio do correto manejo das funções sistêmicas, possibilitando a doação de órgãos e posterior transplante. Na manutenção das funções orgânicas, possuem papel relevante o enfermeiro e o técnico de Enfermagem, que lidam diretamente com o potencial doador. Para isso, é importante capacitação dos profissionais na identificação de morte encefálica, avaliação de alterações fisiológicas bem como garantia de infraestrutura adequada e prestação de cuidados intensivos (PADILHA KG et al., 2010). 
Após diagnóstico de morte encefálica e manutenção das funções vitais, é inevitável a abordagem aos familiares, que precisa ser realizada da maneira mais empática possível. Nesse momento, a atuação do profissional psicólogo mostra-se imprescindível. A ocasião da entrevista ocorre no mesmo momento de luto vivido pela perda de um ente querido, o que exige abordagem psicológica cautelosa. Concomitantemente, levantar a discussão de doação de órgãos requer urgência devido aos obstáculos técnicos que podem ocorrer nos casos de demora até uma decisão (MARTINS EO et al., 2016).

O apoio emocional à família e o suporte de informações acerca de todo o processo de captação e transplante são primordiais para incentivar a doação. Além da assistência eficaz aos familiares nesse momento de dor, as orientações fornecidas pela equipe multiprofissional devem transpor toda a dinâmica de doação (CORREIA WLB, et al., 2018).

Os profissionais da equipe multiprofissional que desempenham funções na captação e distribuição de órgãos e tecidos contam com a Associação Brasileira de Transplantes de Órgãos, instituição que deve se dedicar à qualificação dos recursos humanos atuantes nesse processo (MENDES KDS et al., 2012). Os profissionais dessa equipe desempenham papeis singulares, mas que se complementam. Suas ações de apoio assistencial, técnico-administrativo e emocional são decisivas ao sucesso da organização que procura órgãos e tecidos (SILVA TN et al., 2017).

\section{CONCLUSÃO}

O processo de doação de órgãos consiste em várias etapas que vão desde a identificação do potencial doador, entrevista familiar, manutenção hemodinâmica e por fim a captação de órgãos. Não trata-se de algo simplório. Há necessidade da participação do enfermeiro, médico, psicólogo e técnicos de Enfermagem, de modo que as ações de cada um desses profissionais se interliguem, tornando o processo eficaz em tempo hábil, visto que as atribuições inerentes aos profissionais se complementam são de suma importância. Por meio da experiência do estágio na Liga Acadêmica de Busca Ativa de Potencial Doador de Órgãos e Tecidos para Transplantes, pôde-se vivenciar o árduo trabalho de cada categoria profissional, bem como foi permitido auxílio nas atividades diárias do projeto de extensão. Na Organização de Procura de Órgãos e Tecidos observou-se, principalmente, a sobrecarga de atribuições do profissional enfermeiro, ao passo que também visualizou-se que, na sua ausência, o processo de trabalho estagna-se.

\section{REFERÊNCIAS}

1. ASSOCIAÇÃO BRASILEIRA DE TRANSPLANTE DE ÓRGÃOS (ABTO). Dimensionamento dos Transplantes no Brasil e em cada estado. São Paulo: ABTO, 2017.

2. BRASIL. Lei Federal 9.434, de 4 de fevereiro de 1997. Dispõe sobre a remoção de órgãos, tecidos e partes do corpo humano para fins de transplante e tratamento e dá outras providências. Brasília, 1997.

3. BRITO AAO et al. Participação de acadêmicos de enfermagem na busca de potenciais doadores de órgãos e tecidos. Revista de Enfermagem da UFPI, 2015; 4(2): 119-123.

4. CONSELHO FEDERAL DE ENFERMAGEM (COFEN). Resolução no 292, de 02 de maio de 2004. COFEN, 2004.

5. CONSELHO FEDERAL DE MEDICINA (CFM). Resolução no 2.173, de 23 de novembro de 2017. CFM, 2017.

6. CORREIA WLB et al. Potencial doador cadáver: causas da não doação de órgãos. Enfermagem em Foco, $2018 ; 9(3): 30-34$.

7. GOMES CNS et al. Perspectiva da enfermagem no processo de doação de órgãos e tecidos: relato de experiência. Revista de Enfermagem da UFPI, 2018; 7(1): 71-74.

8. MACEDO JL. As regras do jogo da morte encefálica. Revista de Antropologia, 2016; 59(2): 32-58.

9. MENDES KDS et al. Transplante de órgãos e tecidos: responsabilidades do enfermeiro. Texto \& Contexto Enfermagem, 2012; 21(4): 945-53.

10. NEGREIROS FDS et al. Percepção da equipe multiprofissional sobre as competências do enfermeiro no transplante hepático. Revista Brasileira de Enfermagem, 2017; 70(2): 258-264.

11. PADILHA KG et al. Enfermagem em UTI: Cuidando do paciente crítico. $1^{\text {a }}$ ed. São Paulo: Manole, 2010.

12. PINHEIRO ES et al. Liga de busca ativa de órgãos e tecidos: relato de experiência de acadêmicos de enfermagem. Revista Ciência \& Saberes, 2015; 1(2): 157-160.

13. SILVA TN et al. Saúde Mental dos profissionais de saúde que trabalham com transplantes de órgãos: revisão integrativa. Revista Pró-UniverSUS, 2017; 08(2): 35-40.

14. WATSON CJE, DARK JH. Organ transplantation: historical perspective and current practice. British Journal of Anaesthesia, 2012; 108(Sup.1): 29-42. 